\title{
Galectin-9 Is Critical for Mucosal Adaptive Immunity through the T Helper 17-IgA Axis
}

\author{
Chih-Chia Liang, ${ }^{* \dagger \ddagger \S}$ Chi-Shan Li, ${ }^{\S}$ I-Chun Weng, ${ }^{\S}$ Huan-Yuan Chen, ${ }^{\S}$ Hsueh-Han Lu, ${ }^{\S}$ Chiu-Ching Huang, ${ }^{* \dagger}$ and Fu-Tong Liu ${ }^{\star \S \rrbracket}$
}

From the Ph.D. Program in Translational Medicine, * China Medical University and Academia Sinica, Taichung, Taiwan; the Department of Medicine, ${ }^{\dagger}$ College of Medicine, China Medical University, Taichung, Taiwan; the Division of Nephrology, ${ }^{\ddagger}$ Department of Internal Medicine, China Medical University Hospital, Taichung, Taiwan; the Institute of Biomedical Sciences, ${ }^{\S}$ Academia Sinica, Taipei, Taiwan; and the Department of Dermatology, ${ }^{\llbracket}$ School of Medicine, University of California-Davis, Sacramento, California

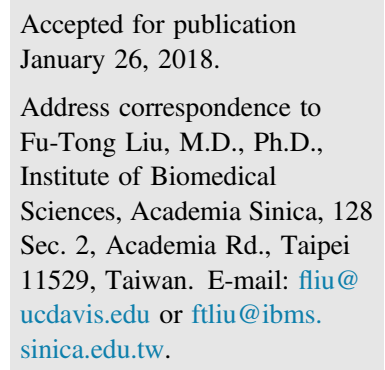

\begin{abstract}
Impairment of the intestinal mucosal immunity significantly increases the risk of acute and chronic diseases. IgA plays a major role in humoral mucosal immunity to provide protection against pathogens and toxins in the gut. Here, we investigated the role of endogenous galectin- 9 , a tandem repeat-type $\beta$ galactoside-binding protein, in intestinal mucosal immunity. By mucosal immunization of $\operatorname{Lgals9^{-/-}}$ and littermate control mice, it was found that lack of galectin- 9 impaired mucosal antigen-specific IgA

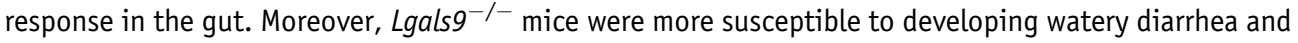
more prone to death in response to high-dose cholera toxin. The results indicate the importance of galectin-9 in modulating intestinal adaptive immunity. Furthermore, bone marrow chimera mice were established, and galectin- 9 in hematopoietic cells was found to be critical for adaptive IgA response. In addition, immunized $\operatorname{Lgals9^{-/-}}$ mice exhibited lower expression of Il17 and fewer T helper 17 (Th17) cells in the lamina propria, implying that the Th17-IgA axis is involved in this mechanism. Taken together, these findings suggest that galectin- 9 plays a role in mucosal adaptive immunity through the Th17-IgA axis. By manipulating the expression or activity of galectin-9, intestinal mucosal immune response can be altered and may benefit the development of mucosal vaccination. (Am J Pathol 2018, 188: 1225-1235; https://doi.org/10.1016/j.ajpath.2018.01.017)
\end{abstract}

Galectin-9, a tandem repeat-type $\beta$-galactoside-binding protein, is expressed in a variety of immune cells and exerts biological functions, including cell aggregation, adhesion, apoptosis, and differentiation. ${ }^{1-3}$ Galectin-9 modulates immune functions by altering cell signaling through the formation of galectin-glycoprotein lattices on the surface of immune cells. ${ }^{1}$

The known functions of galectin-9 include induction of $\mathrm{T}$ helper 1 (Th1) cell apoptosis by binding to T-cell immunoglobulin and mucin domain-containing protein $3,{ }^{4}$ suppression of allergic asthma by inhibiting CD44-hyaluronan interaction, ${ }^{5}$ and boosting the function of adaptive regulatory T cells through its interaction with CD44. ${ }^{6}$ However, intracellular galectin-9 can function as a uric acid transporter in renal epithelial cells by inserting itself into membrane lipid bilayers ${ }^{7}$; furthermore, intracellular galectin-9 regulates apical-basal polarity by interaction with Forssman glycosphingolipid. ${ }^{8}$ These results demonstrate that galectin-9 can exert biological functions in both intracellular and extracellular compartments.

$\operatorname{IgA}$, the most abundant Ig isotype in the intestinal lumen, plays a crucial role in adaptive immunity to prevent pathogenic infections and toxins. ${ }^{9-11}$ Intestinal low-affinity IgA maintains gut homeostasis by shaping a balanced community of commensal microbiota; of more importance, high-affinity IgA derived from $\mathrm{T}$-cell-dependent responses binds to pathogenic bacteria to protect against communicable diseases. ${ }^{12-14}$ Of the T-cell subsets, Th17 cells have recently emerged as an important regulator of T-cell-dependent $\operatorname{IgA}$ responses. ${ }^{15-17}$ Although the mechanisms involved are not fully understood, mice deficient in IL-17 exhibit impaired antigen-specific $\operatorname{Ig}$ A responses for protection against foreign

\footnotetext{
Supported by China Medical University Hospital funding DMR-106-028 (C.-C.L.)

Disclosures: None declared.
} 
pathogens. ${ }^{17,18}$ Instead of a direct role in IgA class switching, Th17 cells secrete IL-17A and IL-21 to support germinal center formation and plasma cell differentiation. ${ }^{15-20}$

Considering that the impairment of mucosal immunity in the gut significantly increases the risk of acute and chronic diseases, ${ }^{21,22}$ it is of great importance to understand the mechanistic basis of regulation of intestinal immune responses. Previous studies have described that galectin-9 is expressed in intestinal epithelial cells ${ }^{23}$ and immune cells, ${ }^{2,3}$ thereby raising the question whether galectin-9 is involved in the modulation of mucosal immunity. In the present study, we investigated the role of endogenous galectin-9 in mucosal immunity of the gut. Our results showed that lack of galectin-9 impairs antigen-specific IgA response in the gut and compromises mucosal adaptive immunity. Furthermore, we found that $\operatorname{Lgals} 9^{-1-}$ mice had fewer number of Th17 cells under the condition of cholera toxin (CT) stimulation, suggesting that the Th17- $\operatorname{IgA}$ axis may be implicated in this mechanism.

\section{Materials and Methods}

Mice

Lgals $9^{-/-}$and Lgals $9^{+/+}$mice (B6.CD45.2 background) were obtained from the Consortium of Functional Glycomics and have been described previously. ${ }^{4-6,24}$ Dr. Fang Liao (Academia Sinica, Taipei, Taiwan) kindly provided B6.SJL-Ptprc ${ }^{a}$ Pepc $^{b} /$ BoyJ congenic mice (B6.CD45.1 background), which were intercrossed with $L$ gals $9^{-1-}$ mice (B6.CD45.2 background) to generate CD45.1 Lgals $^{-1-}$ mice. All mice were maintained at Academia Sinica under a specific pathogen-free condition. Eight- to 12-week-old Lgals $9^{-/-}$and $L g a l s 9^{+/+}$littermates were used for all experiments, unless indicated otherwise. The Institutional Animal Care and Use Committee at Academia Sinica approved all animal experiments.

\section{Immunization and Challenge Protocols}

As previously described, ${ }^{24,25}$ mice were deprived of food for 4 hours and subsequently provided with $300 \mu \mathrm{L}$ of alkalized buffer [two parts $7 \% \mathrm{NaHCO}_{3}$ diluted in eight parts Hanks' balanced salt solution (HBSS)] to neutralize gastric acid 30 minutes before mucosal immunization with oral gavage. All drugs for mucosal immunization were diluted in $300 \mu \mathrm{L}$ of phosphate-buffered saline (PBS). Two oral immunizations with $10 \mu \mathrm{g}$ of CT (List Biological Laboratories, Campbell, CA) were administered on day 0 and 10. In some groups, mice were intraperitoneally administered $100 \mu \mathrm{g}$ of chicken $\gamma$-globulin (CGG; Biosearch Technologies, Novato, CA) on day 0 and were then orally fed with both $500 \mu \mathrm{g}$ of CGG and $10 \mu \mathrm{g}$ of CT on day 1,17 , and 27. Ten days after the final immunization, mice were sacrificed by carbon dioxide asphyxiation for subsequent experiments. For in vivo fluid accumulation test, naive or immunized mice were orally administered $150 \mu \mathrm{g}$ of CT to examine protection against CT-induced diarrhea/fluid loss. To determine death because of massive doses of CT, 150,300 , and $600 \mu \mathrm{g}$ of $\mathrm{CT}$ was administered to these immunized mice.

\section{Fecal Sample Preparation}

Fecal pellets were homogenized in PBS that contained 2 mmol/L EDTA (Merck, Darmstadt, Germany), 2 mmol/L phenylmethylsulfonyl fluoride (Sigma-Aldrich, St. Louis, MO), $0.04 \mathrm{mg} / \mathrm{mL}$ trypsin inhibitor (Invitrogen, Carlsbad CA), and protease inhibitor cocktail (Merck) with Tissuelyzer II (Qiagen, Valencia CA). After centrifugation for 20 minutes, the supernatants were collected for further experiments.

\section{Cell Isolation}

Bone marrow (BM) cells were harvested by flushing femurs and tibias with RPMI 1640 medium (Invitrogen) supplemented with $10 \%$ fetal bovine serum (FBS; Thermo Fisher Scientific, Carlsbad, CA) and removed the debris by passing through $40-\mu \mathrm{m}$ cell strainers (BD Biosciences, San Jose, CA). To isolate mononuclear cells from Peyer's patch (PP), tissues were shaken for 30 minutes at $37^{\circ} \mathrm{C}$ in the digestion medium, that is, $\mathrm{Ca}^{2+} / \mathrm{Mg}^{2+}$-containing HBSS (Life Technologies) supplemented with $2 \%$ FBS, $10 \mathrm{mg} / \mathrm{mL}$ collagenase D (Roche, Indianapolis, IN), $1 \mathrm{U} / \mathrm{mL}$ Dispase (Roche), and 5 $\mathrm{mg} / \mathrm{mL}$ DNase I (Sigma-Aldrich). To isolate intestinal lamina propria (iLP) cells, intestinal tissues were incubated for 20 minutes at $37^{\circ} \mathrm{C}$ with gentle shaking for three times in $\mathrm{Ca}^{+} /$ $\mathrm{Mg} 2^{+}$-free HBSS (Invitrogen) that contained 2\% FBS, 1 $\mathrm{mmol} / \mathrm{L}$ dithiothreitol (Sigma-Aldrich), and $5 \mathrm{mmol} / \mathrm{L}$ EDTA to remove epithelial cells and intraepithelial lymphocytes. Intestinal tissues were then cut into small pieces and incubated in the digestion medium by shaking for 30 minutes at $37^{\circ} \mathrm{C}$. Digested cells of PP and iLP tissues, after passing through $40-\mu \mathrm{m}$ cell strainers, were resuspended in RPMI 1640 medium supplemented with 10\% FBS and carefully loaded between discontinuous 30\% and 100\% Percoll density gradient (GE Healthcare, Little Chalfont, UK). After centrifugation at $670 \times g$ for 20 minutes at room temperature, mononuclear cells at the interface were collected.

\section{Enzyme-Linked Immunosorbent Assay}

Galectin-9 levels, total IgA amounts, and antigen-specific $\operatorname{Ig} \mathrm{A}$ titers were determined in serum and fecal samples by enzymelinked immunosorbent assay as previously described. ${ }^{23,25-27} \mathrm{In}$ brief, 96-well microplates were coated with $1 \mu \mathrm{g} / \mathrm{mL}$ goat anti-galectin-9 antibody (R\&D Systems, Minneapolis, MN), 2 $\mu \mathrm{g} / \mathrm{mL}$ goat anti-mouse IgA (Southern Biotech, Birmingham, $\mathrm{AL}), 20 \mu \mathrm{g} / \mathrm{mL}$ CGG, or $10 \mu \mathrm{g} / \mathrm{mL}$ CT and were incubated at $4^{\circ} \mathrm{C}$ overnight. To block the monosialotetrahexosylganglioside (GM1) binding sites on CT, $10 \mu \mathrm{g} / \mathrm{mL}$ CT and $10 \mathrm{nmol} / \mathrm{mL}$ GM1 (Avanti Polar Lipids, Alabaster, AL) were incubated 
together for 1 hour at room temperature before coating the microplates. After blocking with $3 \%$ bovine serum albumin (Sigma-Aldrich) in PBS for 2 hours at room temperature, serial sample dilutions were incubated at room temperature for 3 hours. Diluted horseradish peroxidase-conjugated goat antimouse IgA (Southern Biotech) was added at room temperature for 1 hour. To measure galectin-9 levels, plates were incubated with $0.5 \mu \mathrm{g} / \mathrm{mL}$ biotinylated goat anti-galectin-9 antibody (R\&D Systems), followed by adding horseradish peroxidase-conjugated streptavidin (R\&D Systems). The reaction was developed with $3,3^{\prime}, 5,5^{\prime}$-tetramethylbenzidine (eBioscience, San Diego, CA), followed by adding $1 \mathrm{~N} \mathrm{HCl}$, and optical density values at $450 \mathrm{~nm}$ were measured with the Infinite Multimode Reader (Tecan, Männedorf, Switzerland). Serial dilutions of purified mouse IgA (BD Pharmingen, San Diego, CA) or recombinant galectin-9 (R\&D Systems) were used to establish standard curves. To calibrate the variation in fecal pellets, fecal IgA values were normalized to total protein concentrations in feces.

\section{In Vitro IgA Class Switching}

To prepare naive $\operatorname{IgD}{ }^{+} \mathrm{B}$ cells, mononuclear cells from PP were labeled with anti-CD93 microbeads and biotin-conjugated antibodies against CD43 (Ly-48), CD4 (L3T4), Ter-119 (all from Miltenyi Biotec, Bergisch Gladbach, Germany), and CD138 (281-2; BD Pharmingen). Anti-biotin microbeads (Miltenyi Biotec) were used to collect the negative fraction, which was labeled with phosphatidylethanolamine-conjugated anti-IgD antibody (11-26c; eBioscience) and subsequently labeled with anti-phosphatidylethanolamine microbeads (Miltenyi Biotec). $\operatorname{IgD}^{+} \mathrm{B}$ cells were isolated with the QuadroMACS Separator (Miltenyi Biotec) and were used as native B cells ( $>98 \% \mathrm{IgD}^{+}$by flow cytometry; data not shown). Naive $\mathrm{IgD}^{+} \mathrm{B}$ cells were plated in round bottom 96-well plates at a density of $2 \times 10^{5}$ per well and were directly stimulated with lipopolysaccharide (LPS; InvivoGen, San Diego, CA), transforming growth factor- $\beta 1$ (TGF- $\beta 1$; R\&D Systems), Bcell-activating factor (Alexis Biochemicals, Lausen, Switzerland), or a proliferation-inducing ligand (Alexis Biochemicals) at indicated concentration for 7 days. The level of $\alpha$ germline transcripts $(\alpha-G T)$ expression was used to examine ongoing IgA class switching in LPS-stimulated B cells.

\section{ELISpot Assay}

Enzyme-linked immunospot (ELISpot) assays were performed to enumerate CT-specific IgA-secreting cells. CT was incubated with GM1 before coating on 96-well polyvinylidene difluoride membrane plates (MAIPS4510; Millipore, Billerica, MA) at $4^{\circ} \mathrm{C}$ overnight. After washing and blocking the plates, various concentrations of mononuclear cells were cultured at $37^{\circ} \mathrm{C}$ in $5 \% \mathrm{CO}_{2}$ for 4 hours. RPMI 1640 medium supplemented with $5 \%$ bovine serum albumin was used for all dilutions. Anti-CT IgA-secreting cells were visualized by adding horseradish peroxidase-conjugated goat anti-mouse $\operatorname{IgA}$ antibody at 1:5000 dilution, followed by adding 3-amino-9-ethylcarbazole substrate (BD Biosciences). The size and number of spots were analyzed with the AID EliSpot Reader System (Autoimmun Diagnostika, Strasbourg, Germany).

\section{Flow Cytometric Analysis}

Isolated mononuclear cells from PP and iLP tissues were suspended in PBS supplemented with $2 \%$ bovine serum albumin, followed by incubation with CD16/CD32 antibody (2.4G2; BD Pharmingen) for 15 minutes to block Fc $\gamma$ receptor. For surface staining, fluorophore-labeled antibodies for CD4 (GK1.5), CD45.1 (A20), or CD45.2 (104) were obtained from BioLegend (San Diego, CA). The fixable viability dye (eBioscience) was used to exclude dead cells, followed by fixation with $4 \%$ formaldehyde. To detect Th1 and Th17 cells, mononuclear cells of iLP were reactivated by leukocyte activation cocktail that contained phorbol 12myristate 13-acetate, ionomycin, and brefeldin A (BD Biosciences) for 4 hours at $37^{\circ} \mathrm{C}$. Intracellular cytokine staining for IL-17A (TC11-18H10.1; BioLegend) and interferon- $\gamma$ (XMG1.2; BioLegend) was performed with Cytofix/Cytoperm buffer (BD Pharmingen) according to the manufacturer's instructions. Flow acquisition was performed on LSRII flow cytometer (BD Biosciences), and results were analyzed by the FlowJo software version 10 (Tree Star, Ashland, OR).

\section{Immunofluorescence Staining}

Small intestinal tissues from sacrificed mice were fixed in $10 \%$ formalin and embedded in paraffin. Tissue sections (5 $\mu \mathrm{m})$ were deparaffinized, followed by heat-induced epitope retrieval with citrate buffer, pH 6.0 (Thermo Fisher Scientific, Waltham, MA) and then blocked with 5\% normal goat serum. For detection of Th17 cells, the sections were incubated overnight with rat anti-CD4 monoclonal antibody (4SM95; eBioscience) and rabbit anti-IL-17 polyclonal antibody (Abcam, Cambridge, MA). Slides were washed and then incubated with fluorescein isothiocyanate- and rhodamineconjugated secondary antibodies (Invitrogen) for 2 hours at room temperature. Finally, coverslips were mounted with the mounting medium that contained DAPI (Invitrogen) and visualized Th17 cells with the use of an LCM 700 confocal microscope (Carl Zeiss, Gottingen, Germany).

\section{Quantitative RT-PCR}

RNA was extracted with the use of RNeasy mini kits (Qiagen), followed by removal of contaminating DNA by DNase I treatment (Sigma-Aldrich). Purified RNA was reverse transcribed into cDNA with the use of iScript cDNA Synthesis Kit (Bio-Rad, Hercules, CA). Quantitative RT-PCR analyses were conducted in the CFX real-rime PCR detection system (Bio-Rad) with the use of specific primers (synthesis by Genomics Taiwan) (Table 1) and corresponding Universal 
Table 1 Primer Sequences for Quantitative RT-PCR

\begin{tabular}{|c|c|c|}
\hline Gene & Forward primer & Reverse primer \\
\hline Il17a & 5'-CAGGGAGAGCTTCATCTGTGT-3' & $5^{\prime}$-GCTGAGCTTTGAGGGATGAT-3' \\
\hline Il22 & 5'-TGCCTTTCCTGACCAAACTC-3' & 5'-CTGGATGTTCTGGTCGTCAC-3' \\
\hline Il23a & $5^{\prime}-$ TCCCTACTAGGACTCAGCCAAC-3' & $5^{\prime}-$ AGAACTCAGGCTGGGCATC $-3^{\prime}$ \\
\hline Ifng & $5^{\prime}$-ATCTGGAGGAACTGGCAAAA- $3^{\prime}$ & $5^{\prime}$-TTCAAGACTTCAAAGAGTCTGAGGTA-3' \\
\hline$\alpha-G T$ & $5^{\prime}$-CCAGGCTAGACAGAGGCAAG- $3^{\prime}$ & $5^{\prime}$-CGGAAGGGAAGTAATCGTGA-3' \\
\hline Gapdh & 5'-GTATGACTCCACTCACGGCAAATT-3' & 5'-GATGGGCTTCCCGTTGATGA-3' \\
\hline $\operatorname{Tgfb1}$ & $5^{\prime}$-TGGAGCAACATGTGGAACTC- $3^{\prime}$ & $5^{\prime}$-GTCAGCAGCCGGTTACCA-3' \\
\hline Aldh1a2 & $5^{\prime}$-CATGGTATCCTCCGCAATG-3' & $5^{\prime}$-GCGCATTTAAGGCATTGTAAC-3' \\
\hline Tnfsf13b & $5^{\prime}$-CGCCGACTATACGAAAAGGA-3' & $5^{\prime}$-CCTGTTTGCCTCACCACTATT-3' \\
\hline Tnfsf13 & $5^{\prime}$-GAAGGATGGGGCGAAATC-3' & $5^{\prime}-$ TGTCACGTCAGAGTCCTTGG-3' \\
\hline
\end{tabular}

ProbeLibrary probes (Roche). The mRNA levels were normalized to those of Gapdh.

\section{BM Chimera Mice}

To establish BM chimera mice, 8- to 12-week-old recipient mice (CD45.1 background) were deprived of food for 2 hours and then exposed to $600 \mathrm{rad} \gamma$-irradiation twice at an interval of 4 hours (total $1200 \mathrm{rad}$ ). On the subsequent day, $5 \times 10^{6} \mathrm{BM}$ donor cells (CD45.2 background) were injected through the tail vein, and mice were fed with antibiotic water (2 $\mathrm{g} / \mathrm{L}$ neomycin; Sigma-Aldrich) for 2 weeks. Engraftment efficiency was examined by flow cytometry after 8 weeks, and these chimera mice were used for further experiments after 12 weeks.

\section{In Vivo IL-17 Neutralization}

For IL-17 neutralization, anti-IL-17 antibody (MAB421; R\&D Systems) or rat IgG2a antibody (MAB006; R\&D Systems), $100 \mu \mathrm{g}$ in $200 \mu \mathrm{L}$ of PBS, was injected intraperitoneally every other day for five injections since the time of the second CT dose (ie, day 10) as previously described. $^{28}$ On day 20, mice were sacrificed for further analysis.

\section{Statistical Analysis}

Two-tailed $t$-test or $U$-test was performed as appropriate to examine statistical significances of differences between the groups. Mortality rates were compared between the groups with the log-rank test. Statistical analyses were performed with Prism software version 5 (GraphPad Software, Inc., La Jolla, CA), and $P$ values $<0.05$ were considered statistically significant.

\section{Results}

Lack of Galectin-9 Specifically Impairs Mucosal Antigen-Specific IgA Response

To investigate the role of galectin- 9 in $\operatorname{IgA}$ production, serum and fecal IgA levels were measured in naive $\operatorname{Lgals} 9^{+/+}$and
L gals $9^{-1-}$ mice. Under the nonimmunized condition, lack of galectin-9 did not affect IgA levels (Supplemental Figure S1, A and B). Mucosal immunization was performed in mice, and subsequently systemic and mucosal antigen-specific IgA titers were measured. Figure 1A depicts the experimental protocol of mucosal immunization with both CGG and CT. No differences were found in serum CGG-specific IgA titers (Figure 1B), serum CT-specific IgA titers (data not shown), and total fecal IgA levels between the two genotypes (Supplemental Figure S1C). However, Lgals $9^{-/-}$mice had significantly lower fecal CGG-specific and CT-specific IgA titers than Lgals $9^{+/+}$mice (Figure 1, C and D), suggesting that lack of galectin-9 impaired mucosal antigen-specific IgA response.

An alternative protocol (with $\mathrm{CT}$ alone) to induce antigen-specific $\mathrm{IgA}$ response was tested (Figure 1E). Impaired mucosal antigen-specific $\operatorname{IgA}$ response was also found in $\operatorname{Lgals} 9^{-1-}$ mice under this condition (Supplemental Figure S1D). Although previous studies have revealed obvious increased serum and tissue galectin-9 levels in inflammatory diseases, ${ }^{29,30}$ this study showed that the CT-induced immune response did not lead to an increase in serum or fecal galectin-9 levels (Supplemental Figure S1E). The number of CT-specific IgA-secreting cells was next investigated in intestinal lymphoid tissues by ELISpot assay. The numbers of CT-specific $\operatorname{IgA}$-secreting cells in both iLP and PP tissues were fewer in mice that lacked galectin-9 (Figure 1F). Taken together, these data suggested that lack of galectin-9 specifically impaired mucosal antigen-specific IgA response.

\section{Protective Immunity Is Compromised against CT in Mice That Lack Galectin-9}

Mice were orally immunized with $\mathrm{CT}$, and then an in vivo $\mathrm{CT}$ challenge was performed to examine whether the lack of galectin-9 impaired mucosal adaptive immunity (Figure 2A). Consistent with previous studies, ${ }^{12,31}$ this study revealed that nonimmunized mice that received $150 \mu \mathrm{g}$ of CT developed severe diarrhea. Both immunized Lgals $9^{+/+}$and $\operatorname{Lgals} 9^{-/-}$ mice had less intestinal water volume than nonimmunized mice, indicating that immunization enabled mice to tolerate 
A

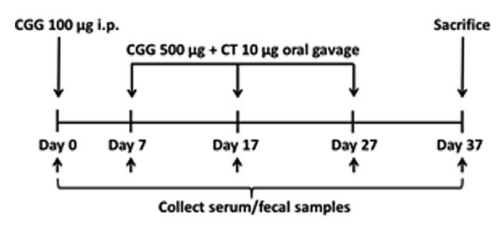

C

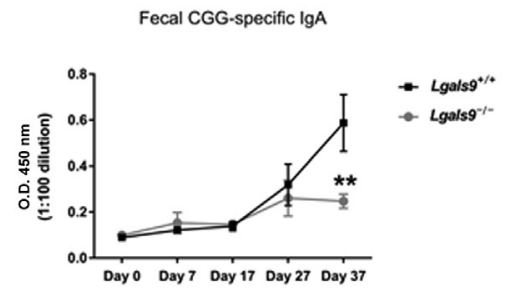

E

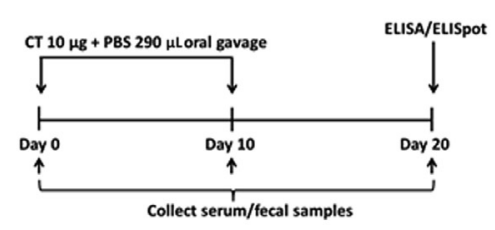

B

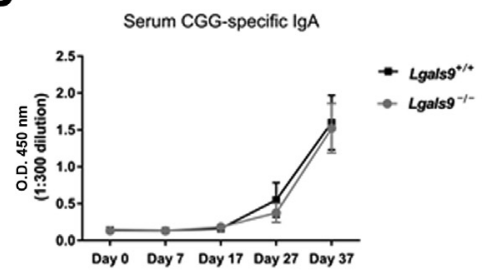

D

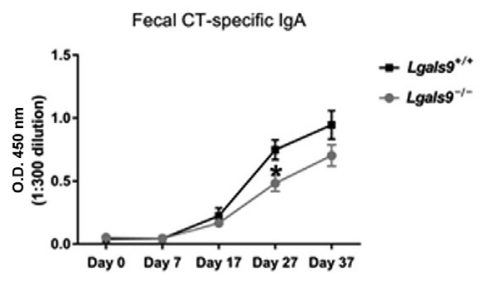

$\mathbf{F}$

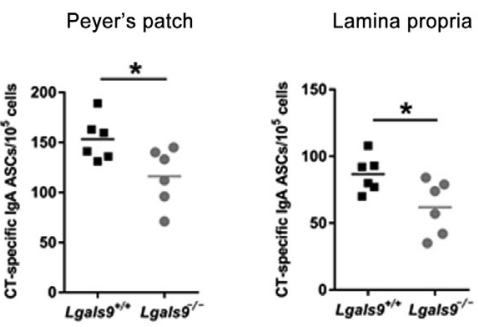

Figure 1 Lack of galectin-9 impairs antigenspecific IgA production. A: The experimental protocol of mucosal immunization. Initially, mice were intraperitoneally injected with chicken $\gamma$-globulin (CGG) on day 0 and subsequently orally immunized with CGG and cholera toxin (CT) on day 7, 17, and 27. B-D: Serum and fecal samples were collected on indicated days to detect CGG- and CT-specific IgA by enzyme-linked immunosorbent assay (ELISA). $E$ and F: Another approach to mucosal immunization. Mice were administered oral gavage with CT on day 0 and 10. 0 n day 20 , mice were sacrificed to quantify CTspecific IgA-forming cells in intestinal lamina propria and Peyer's patch by enzyme-linked immunospot assay (ELISpot). Symbols represent data from individual mice (F). Data are expressed as means \pm SEM (B-D); horizontal lines indicate means (F). Three independent experiments; $n=6$ to 10 mice per group (B-D); $n=6$ mice per group (E and $\mathbf{F}) .{ }^{*} P<0.05$ and ${ }^{*} * P<0.01$. Statistical analyses were performed with $t$-test (B-D) or $U$-test (F). ASC, antibody-secreting cell; 0.D., optical density; PBS, phosphate-buffered saline.
CT (Figure 2, B and C). Of importance, immunized Lgals $9^{-/-}$ mice developed more severe watery diarrhea than immunized Lgals $9^{+/+}$mice, demonstrating the defective protection against CT-induced watery diarrhea in mice that lacked galectin-9 (Figure 2C).

To investigate the defect in protective immunity in L gals $9^{-/-}$mice, a series of high CT doses were administered to examine the mortality rate (Figure $3 \mathrm{~A}$ ). At a dose of 150 or $300 \mu \mathrm{g}$, most immunized mice were alive irrespective of the galectin-9 expression (Figure 3B). Mice that lacked galectin-9 showed a higher mortality rate than wildtype (WT) littermates at a dose of $600 \mu \mathrm{g}(P=0.03$ by the log-rank test) (Figure 3B). These results indicated that mice lacking galectin-9 developed characteristics of impaired mucosal adaptive immunity against antigens.

\section{Galectin-9 Expression by BM-Derived Cells Is Required for Adaptive IgA Response}

To identify which kind of cells were responsible for the functional relevance of galectin-9 to adaptive IgA response, congenic CD45.1 L gals $^{+/+}$or L gals $^{-/-}$host mice were

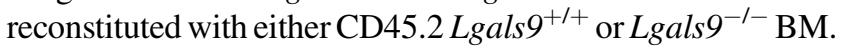
Eight weeks after reconstitution, the engraftment efficiency was analyzed in PP and iLP tissues, and both were found to exhibit $>90 \%$ efficiency (Figure 4A). These BM chimera mice received mucosal immunization with $\mathrm{CT}$ alone 12 weeks after reconstitution, and subsequently ELISpot assay was performed to enumerate antigen-specific $\operatorname{IgA}$ cells. Fewer antigen-specific IgA cells were observed in the intestinal lymphoid tissues of $\operatorname{Lgals} 9^{+/+}$or $\operatorname{Lgals} 9^{-/-}$mice that received $\operatorname{Lgals} 9^{-1-}$ donor cells than those in mice that received Lgals $9^{+/+}$donor cells (Figure 4, B and C). However, the number of antigen-specific IgA cells was comparable between $\operatorname{Lgals} 9^{+/+}$and $\operatorname{Lgals} 9^{-/-}$mice that received $\operatorname{Lgals} 9^{+/+}$ donor cells. These results suggested that galectin- 9 expression by BM-derived cells was critical for adaptive IgA response.

\section{B Cells Lacking Galectin-9 Paradoxically Exhibit Higher IgA Production in Vitro}

Because IgA-secreting B lymphocytes are essential for mucosal adaptive immunity, it was examined whether galectin-9 deficiency in B lymphocytes altered normal IgA response. Our unpublished data revealed that there were no differences in B-cell differentiation, apoptosis, activation, and proliferation between Lgals $9^{+/+}$and Lgals $9^{-1-}$ mice. However, galectin-9-deficient $\operatorname{IgD}^{+}$B cells stimulated with TGF- $\beta$ and LPS in vitro produced more IgA that that produced by WT $\mathrm{IgD}^{+} \mathrm{B}$ cells (Supplemental Figure S2A). The gene expression of $\alpha-G T$, which has been shown to be correlated with $\operatorname{IgA}$ synthesis, was further analyzed. ${ }^{32,33}$ L gals $^{-1-} \operatorname{IgD}^{+}$B cells had a higher level of $\alpha-G T$ than Lgals $9^{+/+} \operatorname{IgD}^{+} \mathrm{B}$ cells in the presence of TGF- $\beta$ and LPS (Supplemental Figure S2B). In 
A

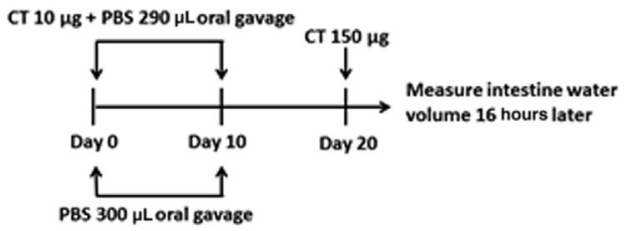

C

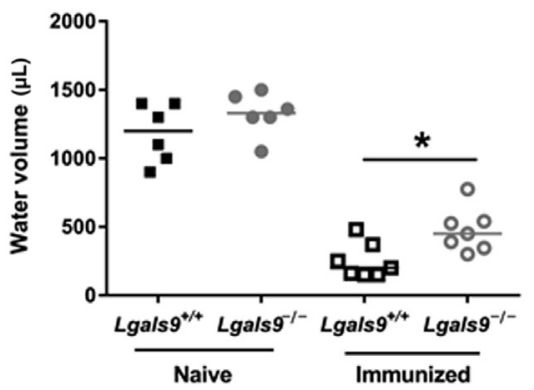

B
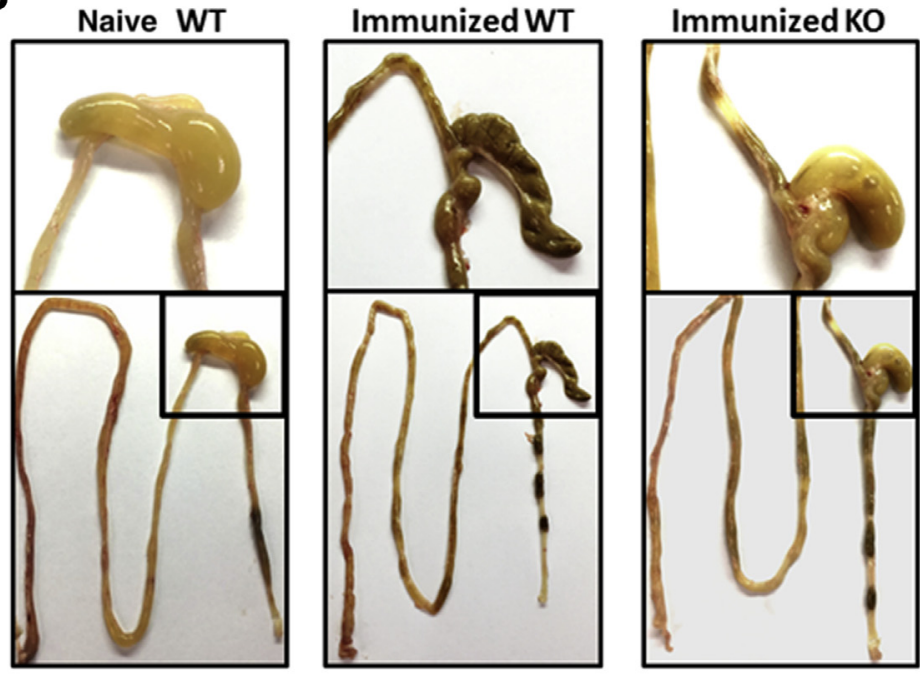

Figure 2 In vivo fluid accumulation test. A: Experimental protocol. Mice were orally immunized with cholera toxin (CT; immunized group) or without CT (naive group) on day 0 and 10 . On day 20, mice were orally fed with $150 \mu \mathrm{g}$ of CT, and intestinal fluid volume was measured after 16 hours. B: Representative images of the intestine after feeding with $150 \mu \mathrm{g}$ of СT. Boxed areas in the lower panels indicate the levels of intestinal water, which are magnified for the upper panels. C: Symbols represent data from individual mice. Horizontal lines indicate medians (C). Three independent experiments; $n=6$ mice in the naive group; $n=7$ mice in the immunized group. ${ }^{*} P<0.05$ (statistical analyses were performed by $U$-test). Original magnification, $\times 2.1$ (B, upper panels). K0, knockout; PBS, phosphatebuffered saline; WT, wild-type. addition, cell numbers were determined with an automated cell counter to investigate if the cell number affected IgA synthesis. The L gals $9^{-1-}$ B-cell density was much lower than WT B-cell density (Supplemental Figure S2C). The results indicated that TGF- $\beta$ augmented the inhibitory effect on LPS-simulated Lgals $9^{-/-}$B-cell growth. In summary, these data suggested that $B$ cells lacking galectin-9 exhibited increased IgA production in the presence of TGF- $\beta$.

\section{Galectin-9-Mediated Mucosal Adaptive Immunity May Involve the Th17-IgA Axis}

Previous studies have shown that a sufficient antigenspecific $\operatorname{Ig}$ A response required the cooperation of mucosal $\mathrm{B}$ and $\mathrm{T}$ cells. ${ }^{9-11}$ These results led us to consider that galectin- 9 expression by $\mathrm{T}$ lymphocytes modulated adaptive IgA response. To elucidate which subset of $\mathrm{T}$ lymphocytes was involved in this phenotype, mononuclear cells were isolated from iLP to analyze IgA-related cytokine genes. The mRNA levels of T-cell-independent cytokines $(T g f b$, Tnfsf13, Tnfsf13b, and Aldh1a2) crucial for IgA production were similar in both immunized mononuclear cells regardless of the galectin-9 expression (data not shown). Of note, L gals $^{-1-}$ cells expressed lower levels of $I l 17 a, I l 22$, and Ifng but higher levels of Il23a than Lgals $9^{+/+}$cells (Figure 5A), indicating that IL-17-producing cells may participate in this mechanism. Although IL-17 is secreted by multiple cell types, such as innate lymphoid cells type 3, Th17 cells, $\gamma \delta \mathrm{T}$ cells, and natural killer cells, ${ }^{34}$ Th17 cells were found to be primarily involved in adaptive $\operatorname{IgA}$

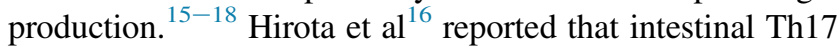
cells acquired the characteristics of $\mathrm{T}$ follicular helper cells (signature genes $I l 21$ and Bcl6) in PP. However, our results showed that there were no differences in mRNA levels of Il21 and Bcl6 between Lgals9 $9^{+/+}$and Lgals $9^{-/-}$PP cells. Moreover, similar proportions of germinal center B cells $\left(\mathrm{CD}_{19}{ }^{+} \mathrm{PNA}^{+} \mathrm{CD}^{+} 5^{+}\right)$were observed in PP of Lgals $^{+/+}$ and L Lals $9^{-1-}$ mice (data not shown).

To investigate the role of Th17 cells in this phenotype, flow cytometric analysis was performed to detect Th17 cells in iLP. Intracellular cytokine staining showed that immunized Lgals $9^{-1-}$ mice had a smaller number of CD4 ${ }^{+} \mathrm{IL}-17^{+}$(Th17) cells in iLP, in comparison with WT mice (Figure 5, B and C). Tissue immunofluorescence staining also revealed the same finding that $\operatorname{Lals} 9^{-1-}$ mice had fewer Th17 cells than Lgals $9^{+/+}$mice (Supplemental Figure S3). To establish galectin-9-mediated mucosal adaptive immunity through the Th17-IgA axis, in vivo IL-17 blockade was performed to investigate the effect of IL-17 on galectin-9-mediated adaptive IgA generation. The difference in mucosal antigen-specific IgA response between immunized $\operatorname{Lgals} 9^{+/+}$and $\operatorname{Lgals} 9^{-/-}$ mice disappeared after mice were subjected to in vivo IL-17 
A

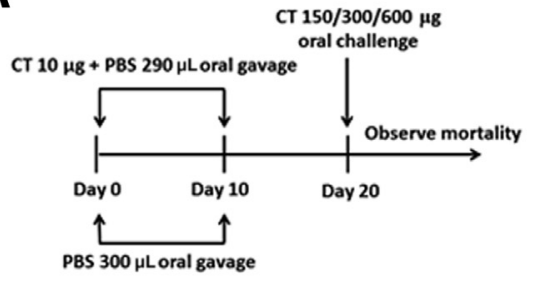

B

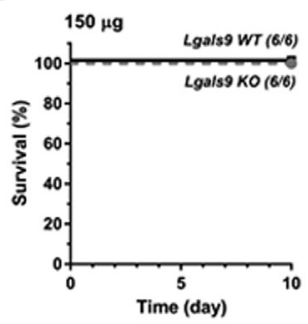

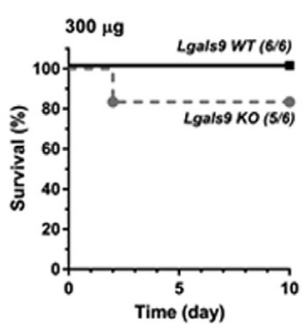

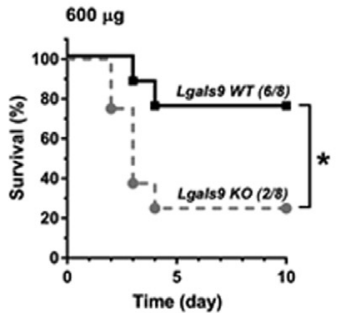

Figure 3 Cholera toxin (CT) mortality test. A: Experimental schedule. Groups of mice were orally immunized with $10 \mu \mathrm{g}$ of $\mathrm{CT}$ on day 0 and 10 and orally challenged with different doses of CT on day 20. Mice were monitored daily to record the mortality rate. B: Graphs show survival curves for $L g a l s g^{+/+}$and Lgals $9^{-1-}$ mice. Two independent experiments; $n=6$ to 8 mice per group (B). ${ }^{*} P<0.05$. Statistical analyses were performed by the log-rank test $(P$ values for 150,300 , and $600 \mu \mathrm{g}$ were $1.00,0.32$, and 0.03, respectively). KO, knockout; PBS, phosphate-buffered saline; WT, wild-type.

neutralization, thereby providing robust evidence of the involvement of Th17 cells in galectin-9-mediated $\operatorname{IgA}$ response (Figure 5, D and E). From previous studies that have established the role of Th17 cells in antigen-specific IgA production, ${ }^{15-18}$ our results suggested that galectin9-mediated adaptive immunity may involve the Th17-IgA axis.

\section{Discussion}

Although exogenous administration of galectin-9 was described to modulate intestinal and pulmonary allergic diseases, ${ }^{23,35}$ little is known about the role of endogenous galectin-9 in the context of mucosal immunity. In the present study, it was found that the lack of galectin-9 impaired mucosal antigen-specific IgA response in the gut. Furthermore, $\operatorname{Lgals} 9^{-I-}$ mice developed more severe watery diarrhea and exhibited higher mortality rates when administered high doses of CT, indicating the importance of galectin-9 in regulating intestinal adaptive immunity. Considering that galectin-9 is expressed by T-cell subsets, B-cell subsets (our unpublished data), dendritic cell subsets, ${ }^{36}$ fibroblasts, ${ }^{5}$ and intestinal epithelial cells, ${ }^{23} \mathrm{BM}$ chimera mice were generated, and it was found that galectin-9 in hematopoietic cells is required for competent

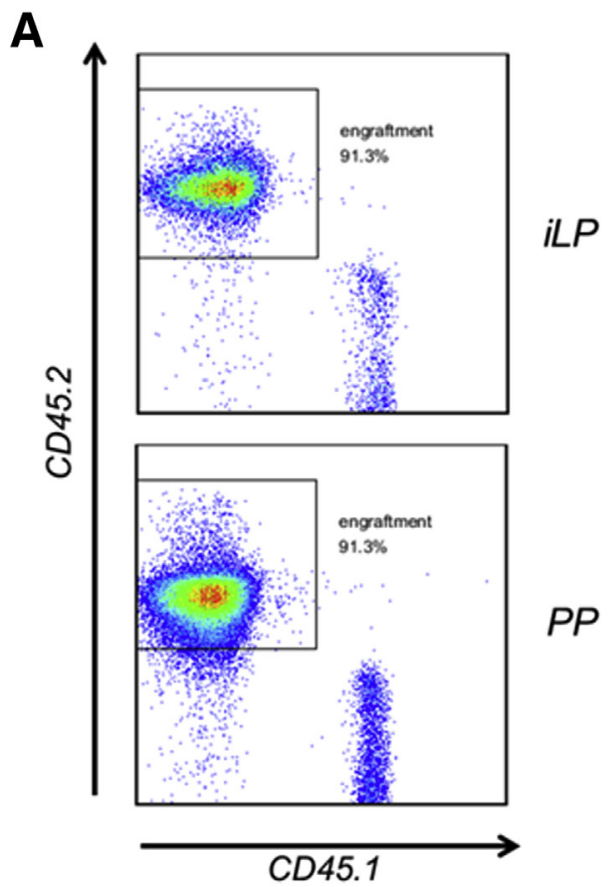

B

C

Peyer's patch
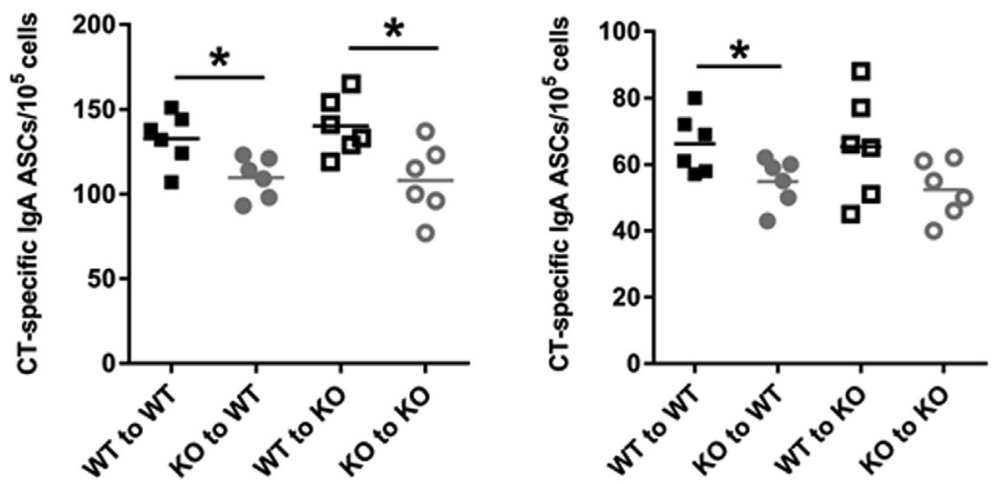

Figure 4 Galectin-9 expression by bone marrow (BM)-derived cells is required for adaptive immunity and host protection. A: Representative flow plots of BM engraftment efficiency in Peyer's patch (PP) and intestinal lamina propria (iLP) cells. Experiments were performed 8 weeks after BM cells of CD45.2 mice were transferred into CD45.1 hosts. Flow plots gate on viable $\mathrm{CD} 45^{+}$cells and numbers in plots indicate the percentage of the cells. B and C: Twelve weeks after BM transplantation, mononuclear cells were isolated from PP and iLP cells of mice that received mucosal immunization to determine cholera toxin (CT)-specific IgAforming cells by enzyme-linked immunospot assay. Symbols represent data from individual mice (B and $\mathbf{C})$. Horizontal lines indicate means (B and $\mathbf{C})$. Three independent experiments; $n=6$ mice per group (B and C). ${ }^{*} P<0.05$ (U-test). ASC, antibody-secreting cell; K0, knockout; WT, wild-type. 
A
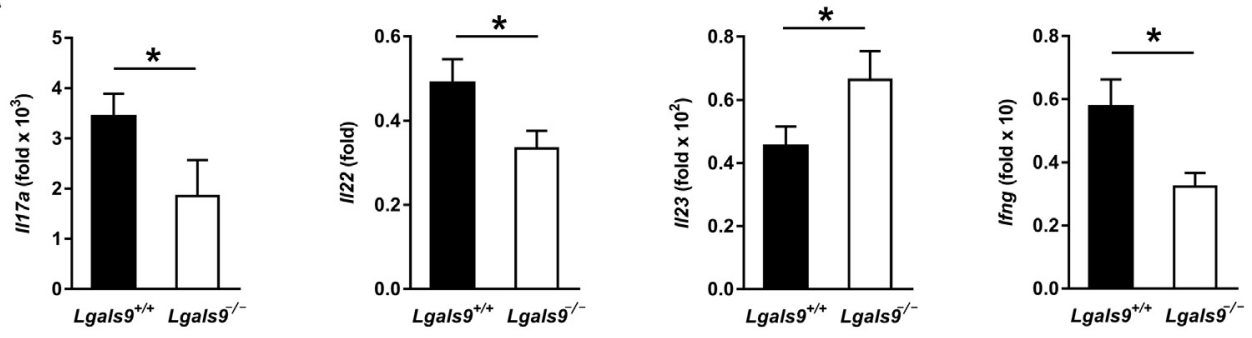

B

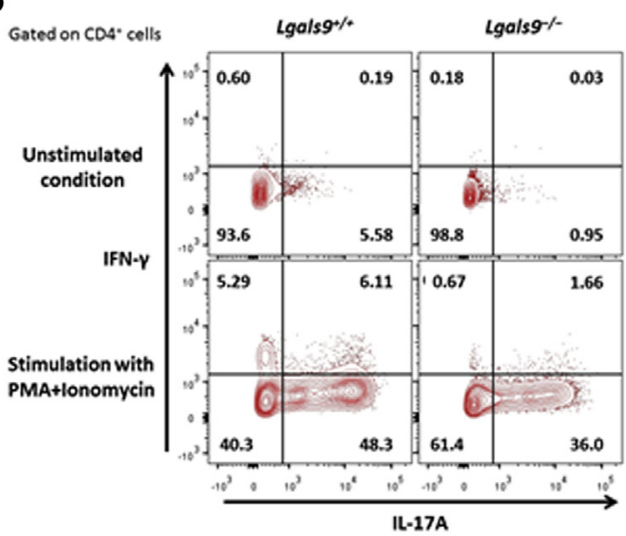

C

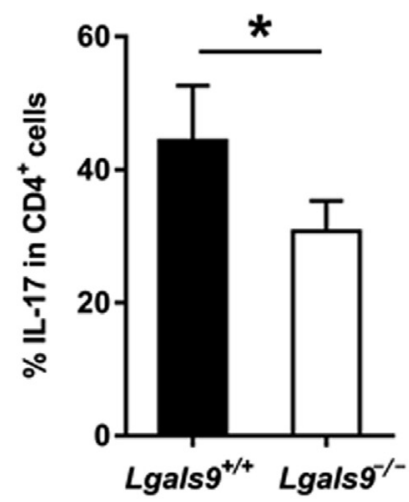

D

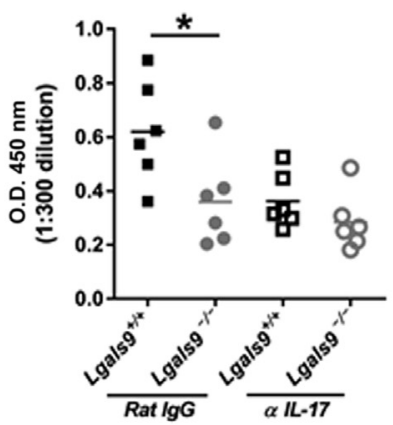

$\mathbf{E}$

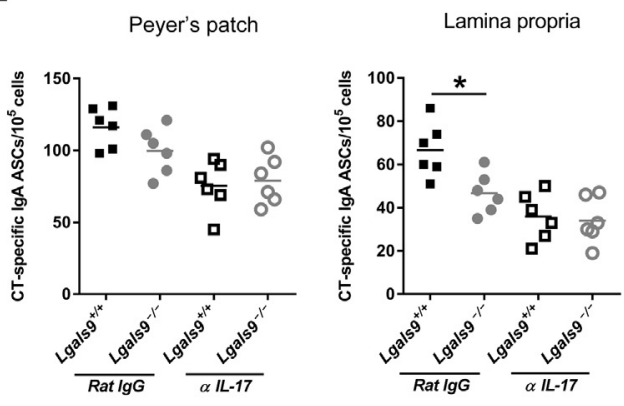

Figure 5 Galectin-9-mediated mucosal adaptive immunity may involve the Thelper 17 (Th17)-IgA axis. A: Gene expression of IL-17-associated cytokines in mononuclear cells of intestinal lamina propria (iLP) was determined in mice that received mucosal immunization. Values are normalized to those of Gapdh. B: Representative flow cytometric plot of $\mathrm{CD}^{+}{ }^{+}$cells stained for intracellular IL-17 and interferon (IFN)- $\gamma$. C: Percentages of Th17 cells among CD4 ${ }^{+}$ cells in the small intestines of immunized mice. $\mathbf{D}$ and E: Mice were orally immunized with $10 \mu \mathrm{g}$ of cholera toxin (CT) on day 0 and 10 and were intraperitoneally injected with $100 \mu \mathrm{g}$ of anti-IL-17 monoclonal (open symbols) or isotype control antibodies (rat IgG2a; closed symbols) every other day for five consecutive doses since day 10. Feces and intestinal tissues were collected on day 20 to measure the fecal CT-specific IgA titer and IgA-secreting cells in anti-IL-17 or isotype control-treated mice. Data are expressed as means \pm SEM (A and C); symbols represent individual mice and horizontal lines indicate the means (D and $\mathbf{E})$. Three independent experiments $(\mathbf{A})$; two independent experiments $(\mathbf{B}-\mathbf{E}) ; n=6$ mice per group $(\mathbf{A}$ and $\mathbf{C}-\mathbf{E})$. ${ }^{*} P<0.05(t$-test). ASC, antibody-secreting cell.

adaptive $\operatorname{Ig}$ A production. The results indicate that intestinal B cells may not contribute to this phenotype because Lgals $9^{-/-}$B cells paradoxically underwent $\operatorname{IgA}$ class switching to a greater extent than Lgals $9^{+/+}$B cells. Moreover, the experiments of in vivo IL-17 blockade and flow cytometric analysis of Th17 cells demonstrated the involvement of Th17 cells in galectin-9-mediated mucosal adaptive IgA response. Taken together, these findings indicate that endogenous galectin-9 plays a critical role in mucosal adaptive immunity through the Th17-IgA axis.
Contrary to the study of Seki et $a l,{ }^{37}$ which used recombinant galectin-9 to demonstrate its extracellular activities, including its suppressive effect on Th17-cell differentiation, the present study reveals that immunized Lgals ${ }^{-1-}$ mice exhibited fewer Th17 cells in the iLP under CT stimulation. Furthermore, Kadowaki et $\mathrm{al}^{38}$ described that exogenous galectin- 9 prolongs the survival of septic mice by expanding natural killer cells and plasmacytoid dendritic cell antigen $-1^{+} \mathrm{CD} 11 \mathrm{c}^{+}$macrophages and that galectin-9 increases the levels of IL-15 and IL-17 but 
decreases tumor necrosis factor $\alpha$, IL-5, IL-10, and high mobility group box 1 . Unlike most cytokines, galectin-9 lacks a classic signal sequence for protein secretion and is predominantly localized within cells, although it can be secreted through a nonclassic secretory pathway. ${ }^{1-3}$ In the present study, the function of endogenous galectin-9 was addressed by comparing $\operatorname{Lgals} 9^{+/+}$and $\operatorname{Lgals} 9^{-/-}$mice, rather than using exogenously added recombinant protein, to delineate the relationship between galectin- 9 and Th17 cells. Regarding the function of galectin-9 that was demonstrated, it is likely that the protein functions intracellularly, although the possibility that it exerts its function extracellularly cannot be excluded.

Here, it was shown that this regulatory phenomenon primarily occurs at the site of iLP rather than PP, because lack of galectin-9 did not disturb the signature gene expression of $\mathrm{T}$ follicular helper cells and percentages of germinal center B cells in PP. It has been suggested that IgA generation with somatic hypermutation could occur outside PPs, for instance in iLP. ${ }^{9,39}$ Not surprisingly, high numbers of eosinophils, innate lymphoid cells, dendritic cells, regulatory $\mathrm{T}$ cells, and Th17 cells are present in iLP and secrete IgA-promoting cytokines (such as TGF- $\beta$, IL-17, B-cell-activating factor, and a proliferation-inducing ligand) to facilitate class switching recombination for T-cell-dependent IgA induction. ${ }^{9,16,40-43}$ Despite these remarkable observations, whether galectin-9 modulates IgA generation by directly affecting Th17 cells or by indirectly disturbing Th17-cell differentiation through other cell types remains to be elucidated.

This study revealed that immunized galectin-9-deficient mice had higher Il23a levels but lower Ill7a and Il22 levels in iLP, suggesting that lack of galectin-9 may impair the IL23-Th17 cell axis as well. It has been well established that IL-23 produced by dendritic cells binds to IL-23 receptors on Th17 cells and subsequently provokes IL-17 and IL-22 production. ${ }^{16,44,45}$ Both IL-17 and IL-22 trigger the upregulation of antimicrobial proteins and promote epithelial barrier function, which maintains the adequate defense mechanism against pathogens and toxins. ${ }^{34,46}$ Therefore, it is reasonable to assume that impairment of the IL-23-Th17 cell axis partly contributes to a higher mortality rate in Lgals $9^{-1-}$ mice that receive high CT doses.

Notably, Sharma et $\mathrm{al}^{27}$ reported that Lgals $9^{-1-}$ mice exhibited higher virus-specific serum IgG and lower virusspecific IgA titers in bronchoalveolar lavage fluid, implying that galectin-9 has different roles in humoral immunity between systemic and mucosal immune systems. Our results indicating impairment of the antigen-specific $\operatorname{IgA}$ response confined to the gut mucosa further support this observation. The reasons why this phenotype is specifically restricted to the gut mucosal system may originate from the differences in the characteristics of immune systems. In contrast to peripheral lymph nodes, most of the B cells undergoing class switching recombination convert to IgA-secreting plasma cells in $\mathrm{PP}$ and iLP. ${ }^{9-11}$ Of more importance, Th2-cell-dominant microenvironment, abundance of Foxp $3^{+} \mathrm{T}$ cells, and IgA immune compartmentalization uniquely exist in the gut mucosa but not in the peripheral lymph nodes. ${ }^{9-11}$

One striking finding of our study was that the lack of galectin-9 attenuated antigen-specific IgA response in vivo, but $\operatorname{Lgals} 9^{-1-}$ B cells exhibited higher IgA generation in vitro (Supplemental Figure S2). This contrasting result may be explained because in vitro culture conditions do not correspond to the complex circumstances observed in living organisms. ${ }^{47}$ In addition, this discrepancy may be attributed to the differences in the unique combination of molecules and spatial organization between in vitro and in vivo studies. ${ }^{47}$ Another interesting discovery was that lack of galectin-9 enhanced the inhibitory effect of TGF- $\beta$ on B-cell proliferation. Beyond the scope of this study, it remains undetermined whether this phenomenon can be observed in non-B cells. It is also worthy to investigate how TGF- $\beta$ interacts with galectin-9 to affect B-cell proliferation.

This study highlights the role of galectin-9 in coordinating mucosal immunity, which is important for developing strategies for mucosal vaccination. CT is widely known as an effective adjuvant owing to its ability to yield a potent IgA immune response through the oral route ${ }^{24,48}$ and to trigger a robust Th17 response in vivo and in vitro. ${ }^{48,49}$ Because these results revealed that CT fails to produce sufficient antigen-specific IgA production and Th17 response in the condition of galectin-9 deficiency, manipulating galectin-9 may alter intestinal mucosal immune response to $\mathrm{CT}$ and, most importantly, tailor the efficiency of adjuvant and vaccine delivery systems. ${ }^{48}$ Further studies that use conditional knockout mice are warranted to confirm our observations and to dissect the mechanism.

\section{Acknowledgments}

We thank Drs. Jr-Wen Shui (Academia Sinica, Taipei, Taiwan) and Tzung-Hai Yen (Chang Gung University, Taoyuan City, Taiwan) for critical comments and Fang Liao for providing B6.CD45.1 mice.

\section{Supplemental Data}

Supplemental material for this article can be found at https://doi.org/10.1016/j.ajpath.2018.01.017.

\section{References}

1. Liu FT, Patterson RJ, Wang JL: Intracellular functions of galectins. Biochim Biophys Acta 2002, 1572:263-273

2. Rabinovich GA, Toscano MA: Turning 'sweet' on immunity: galectin-glycan interactions in immune tolerance and inflammation. Nat Rev Immunol 2009, 9:338-352

3. Liu F-T, Rabinovich GA: Galectins as modulators of tumour progression. Nat Rev Cancer 2005, 5:29-41

4. Zhu C, Anderson AC, Schubart A, Xiong H, Imitola J, Khoury SJ, Zheng XX, Strom TB, Kuchroo VK: The Tim-3 ligand galectin-9 negatively regulates $\mathrm{T}$ helper type 1 immunity. Nat Immunol 2005, $6: 1245-1252$ 
5. Katoh S, Ishii N, Nobumoto A, Takeshita K, Dai SY, Shinonaga R, Niki T, Nishi N, Tominaga A, Yamauchi A, Hirashima M: Galectin9 inhibits CD44-hyaluronan interaction and suppresses a murine model of allergic asthma. Am J Respir Crit Care Med 2007, 176: $27-35$

6. Wu C, Thalhamer T, Franca RF, Xiao S, Wang C, Hotta C, Zhu C, Hirashima M, Anderson AC, Kuchroo VK: Galectin-9-CD44 interaction enhances stability and function of adaptive regulatory $\mathrm{T}$ cells. Immunity 2014, 41:270-282

7. Lipkowitz MS, Leal-Pinto E, Rappoport JZ, Najfeld V, Abramson RG: Functional reconstitution, membrane targeting, genomic structure, and chromosomal localization of a human urate transporter. J Clin Invest 2001, 107:1103-1115

8. Mishra R, Grzybek M, Niki T, Hirashima M, Simons K: Galectin-9 trafficking regulates apical-basal polarity in Madin-Darby canine kidney epithelial cells. Proc Natl Acad Sci U S A 2010, 107: 17633-17638

9. Pabst O: New concepts in the generation and functions of IgA. Nat Rev Immunol 2012, 12:821-832

10. Mantis NJ, Rol N, Corthesy B: Secretory IgA's complex roles in immunity and mucosal homeostasis in the gut. Mucosal Immunol 2011, 4:603-611

11. Macpherson AJ, Geuking MB, McCoy KD: Homeland security: $\operatorname{Ig} \mathrm{A}$ immunity at the frontiers of the body. Trends Immunol 2012, 33: $160-167$

12. Wei M, Shinkura R, Doi Y, Maruya M, Fagarasan S, Honjo T: Mice carrying a knock-in mutation of Aicda resulting in a defect in somatic hypermutation have impaired gut homeostasis and compromised mucosal defense. Nat Immunol 2011, 12:264-270

13. Fagarasan S, Muramatsu M, Suzuki K, Nagaoka H, Hiai H, Honjo T: Critical roles of activation-induced cytidine deaminase in the homeostasis of gut flora. Science 2002, 298:1424-1427

14. Suzuki K, Meek B, Doi Y, Muramatsu M, Chiba T, Honjo T, Fagarasan S: Aberrant expansion of segmented filamentous bacteria in IgA-deficient gut. Proc Natl Acad Sci U S A 2004, 101:1981-1986

15. Milpied PJ, McHeyzer-Williams MG: High-affinity $\operatorname{IgA}$ needs $\mathrm{T}_{\mathrm{H}} 17$ cell functional plasticity. Nat Immunol 2013, 14:313-315

16. Hirota K, Turner JE, Villa M, Duarte JH, Demengeot J, Steinmetz OM, Stockinger B: Plasticity of Th17 cells in Peyer's patches is responsible for the induction of $\mathrm{T}$ cell-dependent $\mathrm{IgA}$ responses. Nat Immunol 2013, 14:372-379

17. Dann SM, Manthey CF, Le C, Miyamoto Y, Gima L, Abrahim A, Cao AT, Hanson EM, Kolls JK, Raz E, Cong Y, Eckmann L: IL-17A promotes protective $\operatorname{IgA}$ responses and expression of other potential effectors against the lumen-dwelling enteric parasite Giardia. Exp Parasitol 2015, 156:68-78

18. Cao AT, Yao S, Gong B, Elson CO, Cong Y: Th17 cells upregulate polymeric Ig receptor and intestinal IgA and contribute to intestinal homeostasis. J Immunol 2012, 189:4666-4673

19. Cao AT, Yao S, Gong B, Nurieva RI, Elson CO, Cong Y: Interleukin (IL)-21 promotes intestinal IgA response to microbiota. Mucosal Immunol 2015, 8:1072-1082

20. Seo GY, Youn J, Kim PH: IL-21 ensures TGF-beta1-induced IgA isotype expression in mouse Peyer's patches. J Leukoc Biol 2009, 85: $744-750$

21. Tremaroli V, Backhed F: Functional interactions between the gut microbiota and host metabolism. Nature 2012, 489:242-249

22. Samuelson DR, Welsh DA, Shellito JE: Regulation of lung immunity and host defense by the intestinal microbiota. Front Microbiol 2015, 6: 1085

23. de Kivit S, Saeland E, Kraneveld AD, van de Kant HJ, Schouten B, van Esch BC, Knol J, Sprikkelman AB, van der Aa LB, Knippels LM, Garssen J, van Kooyk Y, Willemsen LE: Galectin-9 induced by dietary synbiotics is involved in suppression of allergic symptoms in mice and humans. Allergy 2012, 67:343-352

24. Kunisawa J, Gohda M, Hashimoto E, Ishikawa I, Higuchi M, Suzuki Y, Goto Y, Panea C, Ivanov II, Sumiya R, Aayam L, Wake T,
Tajiri S, Kurashima Y, Shikata S, Akira S, Takeda K, Kiyono H: Microbe-dependent $\mathrm{CD}_{11} \mathrm{~b}^{+} \mathrm{IgA}^{+}$plasma cells mediate robust earlyphase intestinal IgA responses in mice. Nat Commun 2013, 4:1772

25. Borsutzky S, Cazac BB, Roes J, Guzman CA: TGF-beta receptor signaling is critical for mucosal IgA responses. J Immunol 2004, 173: 3305-3309

26. Bergqvist P, Gardby E, Stensson A, Bemark M, Lycke NY: Gut IgA class switch recombination in the absence of CD40 does not occur in the lamina propria and is independent of germinal centers. J Immunol 2006, 177:7772-7783

27. Sharma S, Sundararajan A, Suryawanshi A, Kumar N, Veiga-Parga T, Kuchroo VK, Thomas PG, Sangster MY, Rouse BT: T cell immunoglobulin and mucin protein-3 (Tim-3)/Galectin-9 interaction regulates influenza A virus-specific humoral and CD8 T-cell responses. Proc Natl Acad Sci U S A 2011, 108:19001-19006

28. Meng G, Zhang F, Fuss I, Kitani A, Strober W: A mutation in the Nlrp3 gene causing inflammasome hyperactivation potentiates Th17 cell-dominant immune responses. Immunity 2009, 30:860-874

29. Moritoki M, Kadowaki T, Niki T, Nakano D, Soma G, Mori H, Kobara H, Masaki T, Kohno M, Hirashima M: Galectin-9 ameliorates clinical severity of MRL/lpr lupus-prone mice by inducing plasma cell apoptosis independently of Tim-3. PLoS One 2013, 8:e60807

30. Saigusa R, Asano Y, Nakamura K, Hirabayashi M, Miura S, Yamashita T, Taniguchi T, Ichimura Y, Takahashi T, Yoshizaki A, Miyagaki T, Sugaya M, Sato S: Systemic sclerosis dermal fibroblasts suppress Th1 cytokine production via galectin- 9 overproduction due to Fli1 deficiency. J Invest Dermatol 2017, 137:1850-1859

31. Nochi T, Takagi H, Yuki Y, Yang L, Masumura T, Mejima M, Nakanishi U, Matsumura A, Uozumi A, Hiroi T, Morita S, Tanaka K, Takaiwa F, Kiyono H: Rice-based mucosal vaccine as a global strategy for cold-chain- and needle-free vaccination. Proc Natl Acad Sci U S A 2007, 104:10986-10991

32. Weinstein PD, Cebra JJ: The preference for switching to IgA expression by Peyer's patch germinal center B cells is likely due to the intrinsic influence of their microenvironment. J Immunol 1991, 147: $4126-4135$

33. Wakatsuki Y, Strober W: Effect of downregulation of germline transcripts on immunoglobulin A isotype differentiation. J Exp Med 1993 178:129-138

34. Gaffen SL, Jain R, Garg AV, Cua DJ: The IL-23-IL-17 immune axis: from mechanisms to therapeutic testing. Nat Rev Immunol 2014, 14 : $585-600$

35. Ikeda M, Katoh S, Shimizu H, Hasegawa A, Ohashi-Doi K, Oka M: Beneficial effects of Galectin-9 on allergen-specific sublingual immunotherapy in a Dermatophagoides farinae-induced mouse model of chronic asthma. Allergol Int 2017, 66:432-439

36. de la Fuente H, Perez-Gala S, Bonay P, Cruz-Adalia A, Cibrian D, Sanchez-Cuellar S, Dauden E, Fresno M, Garcia-Diez A, SanchezMadrid F: Psoriasis in humans is associated with down-regulation of galectins in dendritic cells. J Pathol 2012, 228:193-203

37. Seki M, Oomizu S, Sakata KM, Sakata A, Arikawa T, Watanabe K, Ito K, Takeshita K, Niki T, Saita N, Nishi N, Yamauchi A, Katoh S, Matsukawa A, Kuchroo V, Hirashima M: Galectin-9 suppresses the generation of Th17, promotes the induction of regulatory $\mathrm{T}$ cells, and regulates experimental autoimmune arthritis. Clin Immunol 2008, 127:78-88

38. Kadowaki T, Morishita A, Niki T, Hara J, Sato M, Tani J, Miyoshi H, Yoneyama H, Masaki T, Hattori T, Matsukawa A, Hirashima M: Galectin-9 prolongs the survival of septic mice by expanding Tim-3expressing natural killer $\mathrm{T}$ cells and $\mathrm{PDCA}-1^{+} \mathrm{CD} 11 \mathrm{c}^{+}$macrophages. Crit Care 2013, 17:R284

39. Fagarasan S, Kinoshita K, Muramatsu M, Ikuta K, Honjo T: In situ class switching and differentiation to IgA-producing cells in the gut lamina propria. Nature 2001, 413:639-643

40. Chu VT, Beller A, Rausch S, Strandmark J, Zanker M, Arbach O, Kruglov A, Berek C: Eosinophils promote generation and maintenance of immunoglobulin-A-expressing plasma cells and contribute to gut immune homeostasis. Immunity 2014, 40:582-593 
41. Artis D, Spits H: The biology of innate lymphoid cells. Nature 2015, 517:293-301

42. Tezuka H, Abe Y, Asano J, Sato T, Liu J, Iwata M, Ohteki T: Prominent role for plasmacytoid dendritic cells in mucosal $\mathrm{T}$ cellindependent IgA induction. Immunity 2011, 34:247-257

43. Tanoue T, Atarashi K, Honda K: Development and maintenance of intestinal regulatory T cells. Nat Rev Immunol 2016, 16: 295-309

44. Datta SK, Sabet M, Nguyen KP, Valdez PA, Gonzalez-Navajas JM, Islam S, Mihajlov I, Fierer J, Insel PA, Webster NJ, Guiney DG, Raz E: Mucosal adjuvant activity of cholera toxin requires Th17 cells and protects against inhalation anthrax. Proc Natl Acad Sci U S A 2010, 107:10638-10643
45. Lee Y, Awasthi A, Yosef N, Quintana FJ, Xiao S, Peters A, Wu C, Kleinewietfeld M, Kunder S, Hafler DA, Sobel RA, Regev A, Kuchroo VK: Induction and molecular signature of pathogenic $\mathrm{T}_{\mathrm{H}} 17$ cells. Nat Immunol 2012, 13:991-999

46. Blaschitz C, Raffatellu M: Th17 cytokines and the gut mucosal barrier. J Clin Immunol 2010, 30:196-203

47. Masedunskas A, Porat-Shliom N, Rechache K, Aye MP, Weigert R: Intravital microscopy reveals differences in the kinetics of endocytic pathways between cell cultures and live animals. Cells 2012, 1:1121-1132

48. Boyaka PN: Inducing mucosal IgA: a challenge for vaccine adjuvants and delivery systems. J Immunol 2017, 199:9-16

49. Tsai HC, Wu R: Cholera toxin directly enhances IL-17A production from human CD4 ${ }^{+}$T cells. J Immunol 2013, 191:4095-4102 